\title{
Влияние растворителя сульфида аммония на пассивацию поверхности GaSb(100)
}

\author{
(С) М.В. Лебедев, Т.В. Львова, С.И. Павлов, И.В. Седова \\ Физико-технический институт им. А.Ф. Иофрфе Российской академии наук, \\ 194021 Санкт-Петербург, Россия \\ E-mail: mleb@triat.ioffe.ru
}

(Получена 17 января 2017 г. Принята к печати 15 фревраля 2017 г.)

Методами рентгеновской фотоэмиссионной спектроскопии и сканирующей электронной микроскопии исследовано влияние растворителя на химический состав сульфидного слоя, образующегося на поверхности $\mathrm{GaSb}(100)$. Обработка поверхности $\mathrm{GaSb}(100)$ в растворах сульфида аммония приводит к формированию толстого (несколько десятков нанометров) покрытия, представляющего собой смесь различных бинарных и тройных сульфидов галлия и сурьмы. Обнаружено различие химического состава пассивирующих сульфидных слоев, сформированных в водном и спиртовом растворах сульфида аммония. Отжиг сульфидного слоя при $360^{\circ} \mathrm{C}$ приводит к частичной десорбции сурьмы и распаду тройных сульфидов на бинарные составляющие.

DOI: 10.21883/FTP.2017.08.44803.8517a

\section{1. Введение}

В течение последних десятилетий оптоэлектроника активно осваивает среднюю инфракрасную (ИК) область спектра (3-5 мкм) как для решения глобальных экологических задач, связанных с мониторингом состояния окружающей среды и контролем процессов промышленного производства, так и для медицины. При разработке светоизлучающих и фотоприемных квантоворазмерных гетероструктур, работающих в этом диапазоне ИК спектра, широко используются узкозонные полупроводники $\mathrm{A}^{\mathrm{III}} \mathrm{B}^{\mathrm{V}}$, такие как $\mathrm{GaSb}$ и многокомпонентные твердые растворы на его основе [1-3]. Одной из главных проблем при создании приборов на основе данных материалов является воспроизводимость параметров и их стабильность, поскольку поверхности этих соединений быстро окисляются на воздухе вследствие их высокой химической активности. На поверхности $\mathrm{GaSb}$ при контакте с воздухом быстро образуется слой, представляющий собой смесь различных оксидов галлия и сурьмы, толщина которого быстро растет со временем и уже через сутки может достигать 3 нм [4]. Дефекты поверхности, вызванные изменением шероховатости и стехиометрии, приводят к появлению поверхностных состояний, являющихся центрами поверхностной безызлучательной рекомбинации. Поэтому для оптимизации характеристик полупроводниковых приборов на основе $\mathrm{GaSb}$ разрабатываются различные методы пассивации поверхности [5-7].

Одним из таких методов является сульфидная пассивация, в процессе которой производится обработка поверхности полупроводников $\mathrm{A}^{\mathrm{III}} \mathrm{B}^{\mathrm{V}}$ или полупроводниковых приборов на их основе различными сульфидными растворами. В результате такой обработки происходит удаление слоя естественного окисла и формирование на поверхности полупроводника защитного пассивирующего покрытия сложного химического состава. Как правило, эти химические процессы приводят к снижению плотности поверхностных состояний и скорости поверхностной безызлучательной рекомбинации, сдвигу уровня Ферми, изменению энергии ионизации и к другим модификациям электронных свойств поверхности полупроводника. Обработку различными сульфидными растворами использовали и для пассивации поверхности $\mathrm{GaSb}$ [8-15]. Однако ряд явлений, обнаруженных при сульфидной пассивации поверхности антимонида галлия, позволяет предположить, что для этого полупроводника процесс формирования пассивирующего сульфидного покрытия существенно отличается от процессов, протекающих при пассивации поверхности других полупроводников $\mathrm{A}^{\mathrm{III}} \mathrm{B}^{\mathrm{V}}$ (арсенидов и фосфидов). Так, например, при сульфидировании поверхностей $\operatorname{GaAs}(100), \operatorname{InAs}(100)$, $\operatorname{InP}(100), \operatorname{GaP}(100)$ растворами сульфида аммония толщина сульфидного покрытия, как правило, не превышает 1-2 монослоя [16], в то время как на поверхности $\mathrm{GaSb}(100)$ формируется сульфидный слой, толщина которого может достигать десятков нанометров [10,14].

Целью данной работы является выяснение механизма процесса сульфидной пассивации поверхности $\mathrm{GaSb}(100)$ в водном и спиртовом растворах сульфида аммония $\left(\mathrm{NH}_{4}\right)_{2} \mathrm{~S}$, а также выяснение влияния природы растворителя на химический состав пассивирующего слоя, образующегося на поверхности полупроводника.

\section{2. Методика эксперимента}

Для исследования использовали подложки $n-\mathrm{GaSb}(100)$, легированные теллуром с концентрацией $(1-3) \cdot 10^{17} \mathrm{~cm}^{-3}$. Перед сульфидированием поверхность образцов очищали ацетоном и изопропиловым спиртом в ультразвуковой ванне. После ультразвуковой очистки производили сульфидирование образца в водном или спиртовом растворе сульфида аммония в течение 30 мин. 
В качестве водного раствора использовали свежий $(40-48) \%$-й $(\sim 6 \mathrm{M})$ водный раствор $\left(\mathrm{NH}_{4}\right)_{2} \mathrm{~S}$. Для приготовления спиртового раствора сульфида аммония этот (40-48)\%-й водный раствор $\left(\mathrm{NH}_{4}\right)_{2} \mathrm{~S}$ разбавлялся изопропиловым спиртом $\left(2-\mathrm{C}_{3} \mathrm{H}_{7} \mathrm{OH}\right)$ в соотношении $1: 9$. После окончания процесса сульфидирования образцы высушивали на воздухе при комнатной температуре и затем загружали в вакуумную камеру для последующих исследований. Время пребывания сульфидированных образцов на воздухе не превышало 5 мин.

Кроме того были проведены исследования изменения кислотности $(\mathrm{pH})$ водного и спиртового растворов сульфида аммония при контакте с поверхностью $\mathrm{GaSb}(100)$. Величину $\mathrm{pH}$ растворов измеряли с помощью стеклянного электрода на рН-метре PР-15 (Sartorius, Германия). Изменение значения $\mathrm{pH}$ в процессе эксперимента в обоих растворах происходило аналогично. Измеренные значения $\mathrm{pH}$ растворов до контакта с образцом $\mathrm{GaSb}$ составили 9.87 и 9.09 для водного и спиртового растворов соответственно. Через 30 мин взаимодействия с $\mathrm{GaSb}$ величина $\mathrm{pH}$ растворов уменьшалась до 9.57 и 8.83 соответственно.

Химический состав сульфидного покрытия изучали методом рентгеновской фотоэмиссионной спектроскопии (РФЭС). Исследования методом РФЭС проводили на линии U49/2 синхротрона BESSY (Берлин). Измерения спектров фотоэмиссии осуществляли на установке SoLiAS [17] с анализатором Phoibos 150 (SPECS). Энергию возбуждающего синхротронного излучения варьировали для изменения анализируемой глубины от поверхности образца за счет изменения длины пробега фотоэлектронов без неупругого рассеяния [18]. Энергии связи остовных уровней отсчитывали от уровня Ферми, положение которого определяли на эталонном образце из золотой фольги для каждой используемой энергии синхротронного излучения. Отжиг сульфидированных образцов осуществляли в отдельной подготовительной камере установки SoLiAS. В ходе отжига давление в данной камере не повышалось более $10^{-8}$ мбар. Температуру отжига контролировали с помощью термопары, расположенной вблизи образца. Подробное описание методологии исследования сульфидированных поверхностей $\mathrm{GaSb}(100)$ методом рентгеновской фотоэмиссионной спектроскопии изложено в работе [14].

Измерение толщины сульфидного покрытия проводили методом сканирующей электронной микроскопии (СЭМ) в геометрии поперечного сечения на микроскопе JSM 7001F (JEOL).

\section{3. Результаты}

Обзорные спектры фотоэмиссии исходной поверхности $\mathrm{GaSb}(100)$ содержат характерные пики остовных уровней галлия, сурьмы и углерода (рис. 1). Остовный уровень кислорода $\mathrm{O} 1 s$ перекрывается с пиком $\mathrm{Sb} 3 d_{5 / 2}$ дублета уровня $\mathrm{Sb} 3 d$.

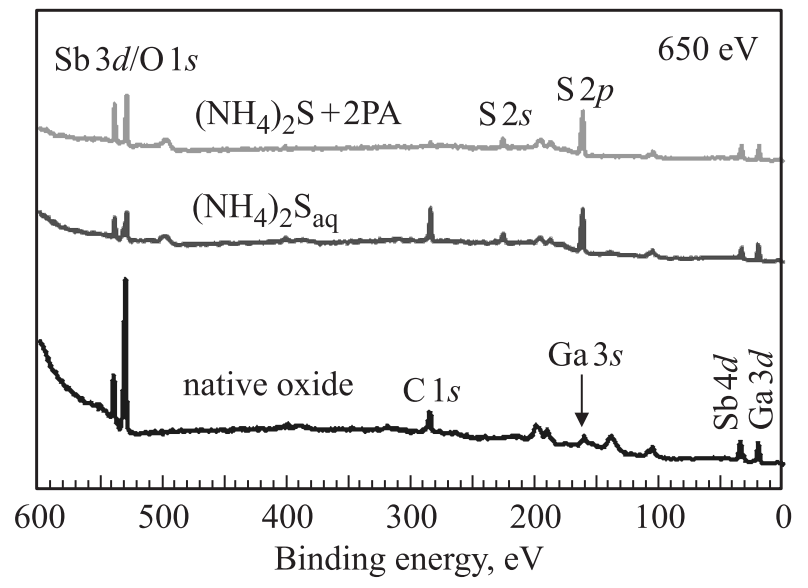

Рис. 1. Обзорные спектры фотоэмиссии исходной покрытой слоем естественного окисла поверхности $\mathrm{GaSb}(100)$, а также поверхностей $\mathrm{GaSb}(100)$, обработанных водным, $\left(\mathrm{NH}_{4}\right)_{2} \mathrm{~S}_{\mathrm{aq}}$, и спиртовым, $\left(\mathrm{NH}_{4}\right)_{2} \mathrm{~S}+2 \mathrm{PA}$, растворами сульфида аммония. Энергия возбуждения 650 эВ.

После сульфидирования поверхности $\mathrm{GaSb}(100)$ как в водном, так и в спиртовом растворах сульфида аммония наблюдалось появление фотоэмиссионных пиков серы $\mathrm{S} 2 p$ и $\mathrm{S} 2 s$ (рис. 1). При этом после сульфидирования в спиртовом растворе фотоэмиссионный пик углерода $\mathrm{C} 1 s$ исчезал практически полностью (рис. 1). После сульфидирования в водном растворе содержание кислорода на поверхности существенно уменьшалось, в то время как после сульфидирования поверхности в спиртовом растворе сульфида аммония кислород удалялся практически полностью [14].

Для исследования химического состава сульфидного слоя непосредственно на поверхности полупроводника измерения проводили при энергии возбуждения 90 эВ. Спектры остовных уровней $\mathrm{Sb} 4 d$ и $\mathrm{Ga} 3 d$ сульфидированных в водном и спиртовом растворах сульфида аммония поверхностей $\mathrm{GaSb}(100)$ приведены на рис. 2. Фотоэмиссионные пики $\mathrm{Sb} 4 d$ и $\mathrm{Ga} 3 d$ поверхности, обработанной в спиртовом сульфидном растворе, сдвинуты в сторону бо́льших энергий связи на +0.45 и +0.35 эВ относительно пиков поверхности, обработанной в водном сульфидном растворе. При этом интенсивность пика фотоэмиссии $\mathrm{Sb} 4 d$ на обработанной спиртовым раствором поверхности в 3 раза выше, чем на поверхности, обработанной водным раствором. С учетом соответствующих сечений ионизации [19] отношение атомных концентраций $\mathrm{Ga}$ и $\mathrm{Sb}$ непосредственно на поверхности (в пределах 2-3 верхних монослоев) после обработки в спиртовом растворе составило 0.15 , а после обработки в водном сульфидном растворе 0.4 .

Разложение спектров остовных уровней $\mathrm{Sb} 4 d$ и $\mathrm{Ga} 3 d$ этих поверхностей, измеренных при двух энергиях синхротронного возбуждения, представлено на рис. 3,4. Разложение спектров осуществляли с помощью функций Фойхта (Voigt), представляющих собой свертки функ- 

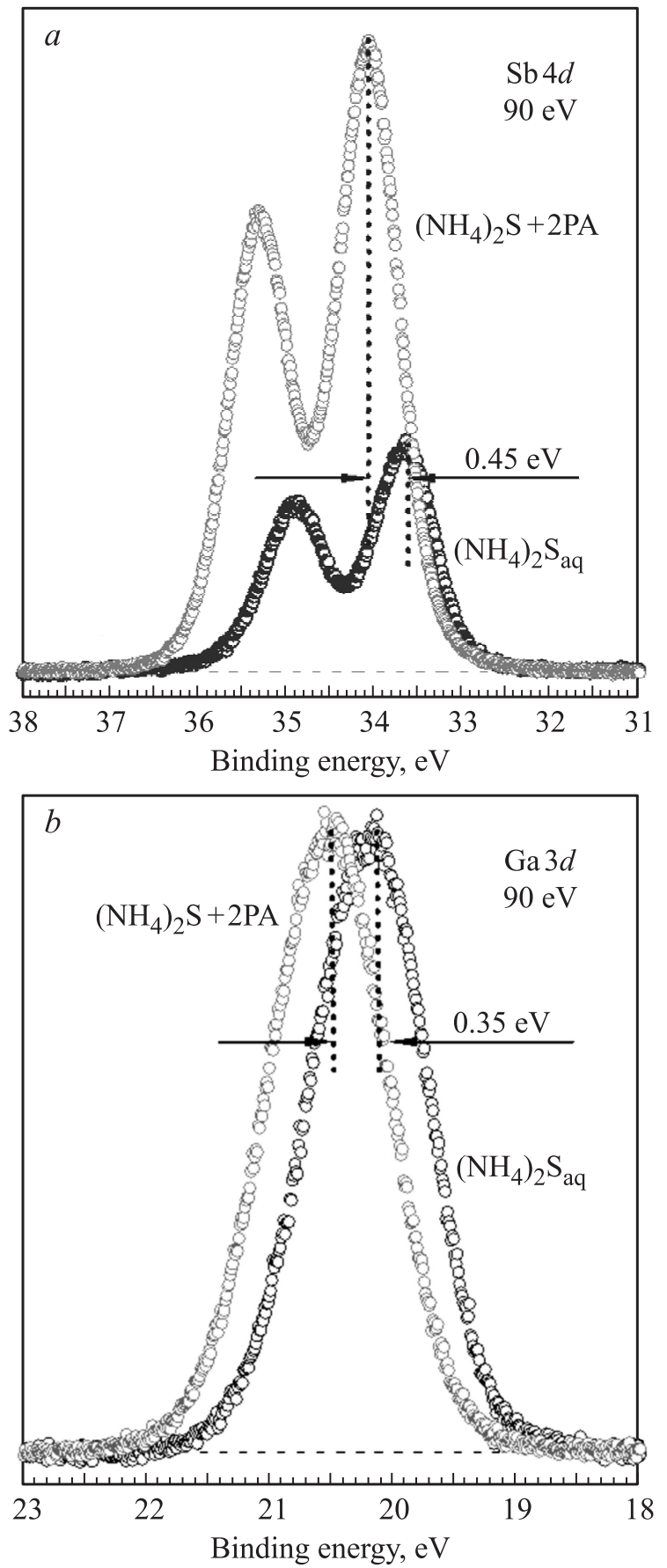

Рис. 2. Спектры остовных уровней $\mathrm{Sb} 4 d(a)$ и $\mathrm{Ga} 3 d(b)$ поверхностей $\mathrm{GaSb}(100)$, обработанных водным и спиртовым растворами сульфида аммония. Энергия возбуждения 90 эВ.

ций Гаусса и Лоренца. Параметры этих функций были близки к значениям, использованным в работах $[20,21]$. Разложение проводили после вычитания фонового фотоэмиссионного сигнала по методу Ширли [22].

Спектры остовных уровней $\mathrm{Sb} 4 d$ могут быть разложены на 4 основные компоненты (рис. $3, a, 4, a)$. Помимо доминирующей имеются еще три компоненты, одна из которых сдвинута в сторону меньших энергий связи примерно на -0.4 эВ, а две другие - в сторону бо́льших энергий связи на +0.4 и +1.1 эВ. Спектры остовных уровней $\mathrm{Ga} 3 d$ помимо основной компоненты содержат три компоненты, сдвинутые относительно основной компоненты на $-0.4,+0.35$ и +0.7 эВ (рис. $3, b, 4, b)$.
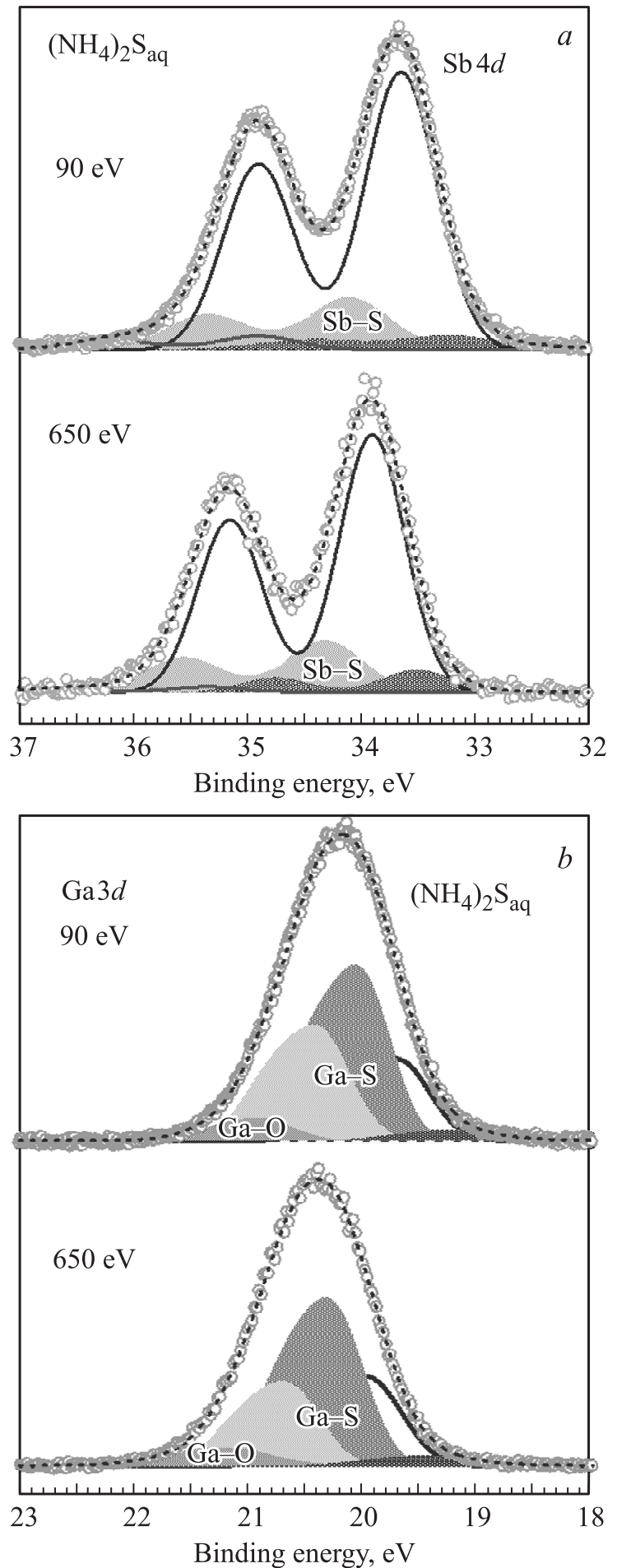

Рис. 3. Разложение спектров остовных уровней $\mathrm{Sb} 4 d$ (a) и $\mathrm{Ga} 3 d(b)$, измеренных при энергиях возбуждения 90 и 650 эВ на поверхности $\mathrm{GaSb}(100)$, обработанной водным раствором сульфида аммония. 

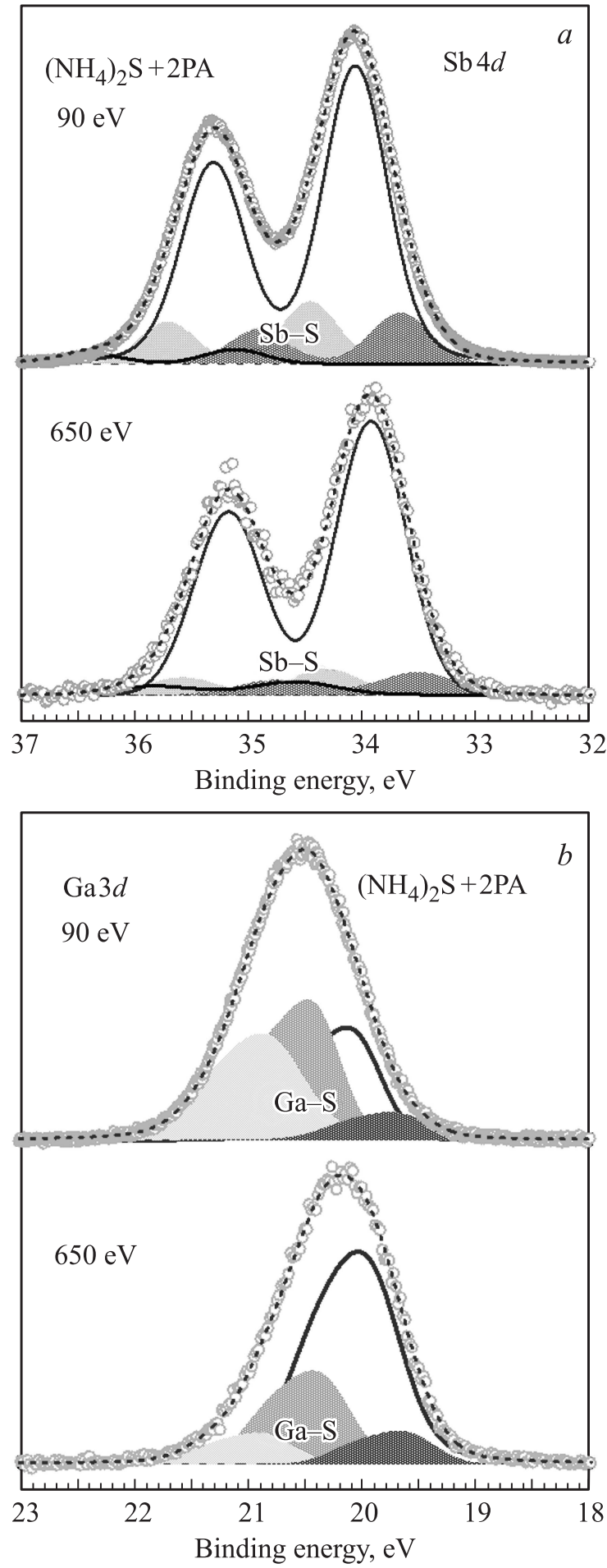

Рис. 4. Разложение спектров остовных уровней $\mathrm{Sb} 4 d$ (a) и $\mathrm{Ga} 3 d(b)$, измеренных при энергиях возбуждения 90 и 650 эВ на поверхности $\mathrm{GaSb}(100)$, обработанной раствором сульфида аммония в изопропиловом спирте.

Кроме того, в спектре уровня Ga $3 d$ сульфидированной в водном растворе поверхности $\mathrm{GaSb}(100)$ имеется дополнительная компонента, сдвинутая в сторону бо́льших энергий связи примерно на +1.2 эВ, которую можно связать с остаточным оксидом галлия, поскольку на данной поверхности присутствует заметное количество остаточного кислорода. В спектрах фотоэмиссии, измеренных при всех энергиях возбуждения, разность энергий связи основных компонент уровней $\mathrm{Sb} 4 d$ и $\mathrm{Ga} 3 d$ на сульфидированных поверхностях составляет $\sim 14.0$ эВ (рис. 2-4), в то время как на чистой, свободной от окислов поверхности $\mathrm{GaSb}(100)$ разность энергий связи объемных компонент $\mathrm{Sb}-\mathrm{Ga}(4 d)$ и $\mathrm{Ga}-\mathrm{Sb}(3 d)$ должна составлять $\sim 13.0$ эВ [20,21]. Это означает, что все наблюдаемые компоненты разложений спектров $\mathrm{Sb} 4 d$ и $\mathrm{Ga} 3 d$ (кроме компоненты спектра $\mathrm{Ga} 3 d$ с химическим сдвигом +1.2 эВ) могут быть обусловлены различными сульфидами галлия и сурьмы, а не с объемной фотоэмиссией $\mathrm{GaSb}$ [14]. Среди этих сульфидов могут быть как бинарные $\left(\mathrm{Sb}_{2} \mathrm{~S}_{3}, \mathrm{Sb}_{2} \mathrm{~S}_{4}, \mathrm{Sb}_{2} \mathrm{~S}_{5}, \mathrm{GaS}, \mathrm{Ga}_{2} \mathrm{~S}_{3}\right)$, так и тройные $\left(\mathrm{GaSbS}_{3}, \mathrm{GaSbS}_{4}\right)$ соединения.

Факт отсутствия в спектрах остовных уровней $\mathrm{Sb} 4 d$ и $\mathrm{Ga} 3 d$ сульфидированных поверхностей $\mathrm{GaSb}(100)$ (рис. 3,4), снятых при всех энергиях синхротронного излучения, компонентов, соответствующих объемному $\mathrm{GaSb}$, свидетельствует о том, что толщина сульфидного покрытия велика. Длина пробега фотоэлектронов с кинетической энергией $\sim 600$ эВ (фотоэлектроны с уровней $\mathrm{Sb} 4 d$ и $\mathrm{Ga} 3 d$, возбуждаемые синхротронным излучением с энергией 650 эВ) составляет $\sim 25 \AA$ [18]. Соответственно толщину сульфидного покрытия можно оценить как $d \geq 3 \lambda \approx 75 \AA$. В действительности эта толщина может быть существенно больше [10]. Отношение атомных концентраций $\mathrm{Ga}$ и $\mathrm{Sb}$ в более глубоких слоях сульфидного покрытия (в пределах слоя толщиной $75 \AA$ ) после обработки в спиртовом растворе было $\sim 1$, а после обработки в водном сульфидном растворе было близко к 2.

На рис. 5, $a, b$ представлены фотографии исследуемых образцов, полученные методом СЭМ в геометрии поперечного сечения. Следует отметить, что в обоих случаях толщина сульфидного покрытия превышает $30 \mathrm{HM}$ (300 ̊).

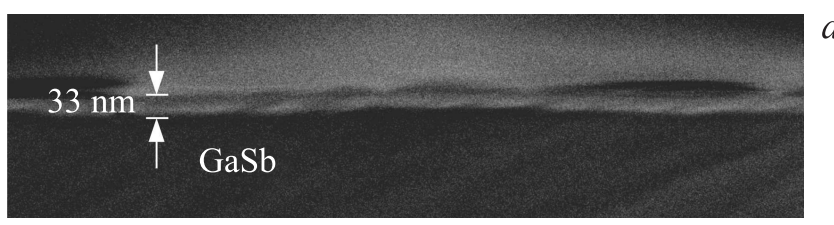

$100 \mathrm{~nm} \quad 5.0 \mathrm{kV}$ SEI SEM WD $10 \mathrm{~nm}$ JEOL 12/04/14

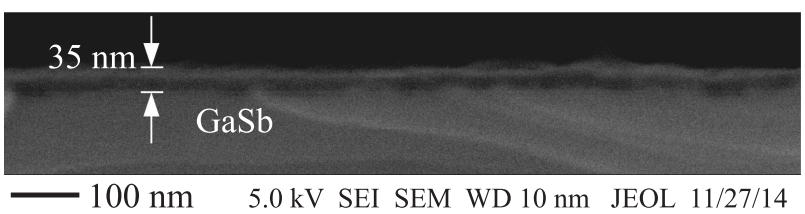

Рис. 5. Фотографии поперечного сечения приповерхностной области образцов $\mathrm{GaSb}(100)$, обработанных водным $(a)$ и спиртовым (b) растворами сульфида аммония, полученные методом сканирующей электронной микроскопии. 

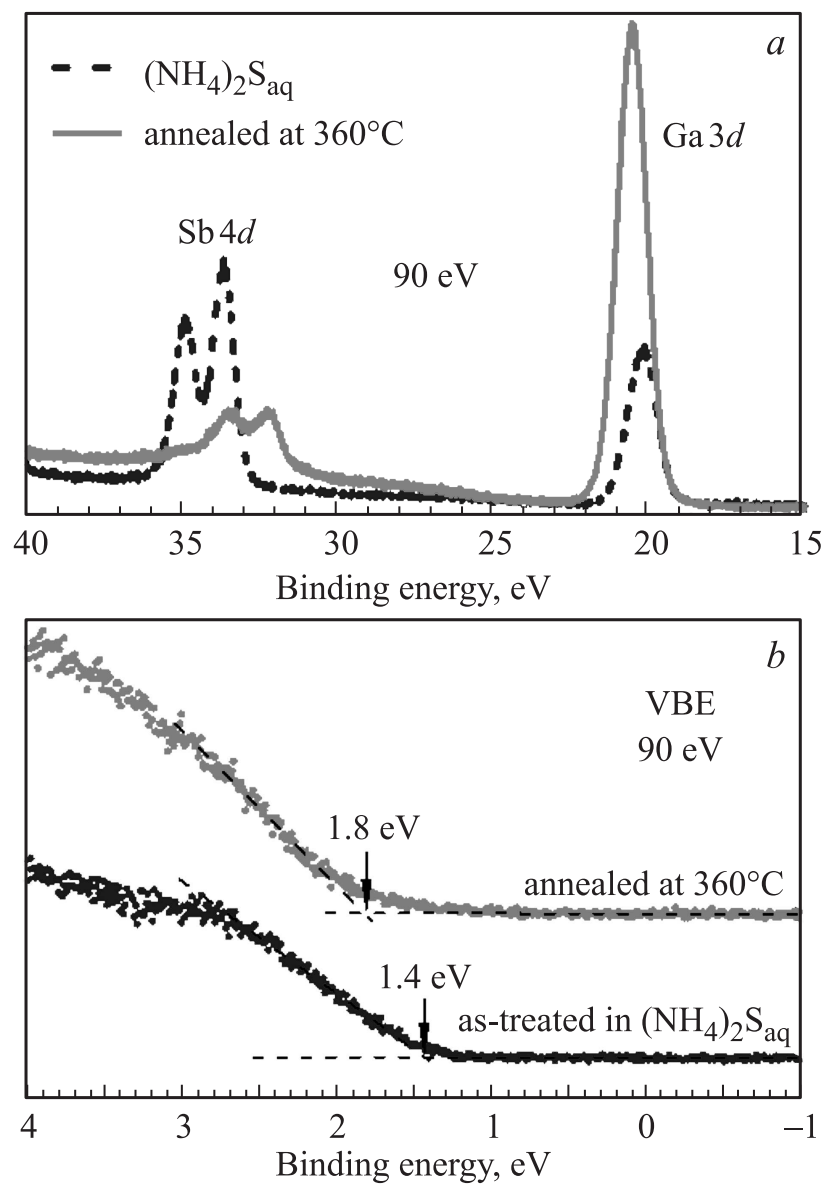

Рис. 6. Обзорные спектры (a) и спектры края валентной зоны $\operatorname{VBE}(b)$, измеренные при энергии возбуждения 90 эВ на обработанной водным раствором сульфида аммония поверхности $\mathrm{GaSb}(100)$ и на этой же поверхности, подвергнутой отжигу в сверхвысоком вакууме при $360^{\circ} \mathrm{C}$.

Отжиг в сверхвысоком вакууме при температуpe $360^{\circ} \mathrm{C}$ сульфидированной в водном растворе поверхности $\mathrm{GaSb}(100)$ приводит к существенному возрастанию отношения атомных концентраций $\mathrm{Ga} / \mathrm{Sb}$ в верхнем приповерхностном слое (более чем в 7.5 раз), а также к существенному изменению формы спектра $\mathrm{Sb} 4 d$ (рис. 6, $a$ ). Это свидетельствует об активной десорбции сульфидов сурьмы с поверхности $\mathrm{GaSb}(100)$ при отжиге, так же как и с поверхности $\operatorname{InSb}(111) \mathrm{A}$ [23]. В результате отжига наблюдается сдвиг линии Ga $3 d$ в сторону бо́льших энергий связи на $\sim 0.35$ эВ (рис. $6, a$ ). Данный сдвиг обусловлен изменением положения края валентной зоны относительно уровня Ферми (рис. 6, $b$ ). Отжиг при более низких температурах не приводил к заметному изменению формы спектров фотоэмиссии, хотя отношение атомных концентраций $\mathrm{Ga} / \mathrm{Sb}$ также увеличивалось.

Анализ спектра уровня $\mathrm{Sb} 4 d$ показал, что структура сульфидного покрытия существенно изменяется после отжига (рис. 7,a). В частности, появляется доминирующая компонента с энергией связи 32.2 эВ, а также имеются еще две компоненты, сдвинутые относительно доминирующей в сторону бо́льших энергий связи на 0.6 и 1.6 эВ. Положение этих двух компонент соответствует сульфидам сурьмы [14]. Можно предположить, что входящее в состав сульфидного слоя тройное соединение $\mathrm{GaSbS}_{x}$ после отжига сначала распадается на сульфид галлия, элементную сурьму, сульфид сурьмы и антимонид галлия, после чего элементная сурьма и сульфид сурьмы начинают десорбироваться, о чем свидетельствует возрастание отношения атомных концентраций $\mathrm{Ga} / \mathrm{Sb}$. C другой стороны, изменение температуры может также вызывать структурную модификацию тройного соединения $\mathrm{GaSbS}_{x}$, как это было показано на примере аналогичного тройного соединения $\mathrm{GaAsO}_{4}$ [24]. Соответственно доминирующую компоненту с энергией связи 32.2 эВ можно отождествить со связями $\mathrm{Sb}-\mathrm{Ga}$, возникшими в результате распада тройного соединения, а компоненты с химическими сдвигами 0.6 и 1.6 эВ можно связать с остаточными сульфидами $\mathrm{GaSbS}_{x}$ и $\mathrm{Sb}_{x} \mathrm{~S}_{y}$. Связи $\mathrm{Sb}-\mathrm{Ga}$ не относятся к объемному полупроводнику, а представляют собой кластеры $\mathrm{GaSb}$, образовавшиеся внутри сульфидного слоя вследствие отжига.

Форма спектра Ga $3 d$ после отжига сульфидированной поверхности практически не изменяется (рис. 7, $b$ ). Однако его интенсивность существенно возрастает за счет обеднения приповерхностной области сурьмой из-за ее десорбции. Кроме того, после отжига наблюдается сдвиг линии Ga $3 d$ в сторону бо́льших энергий связи из-за изменения приповерхностного изгиба зон диэлектрического сульфидного покрытия (рис. 7,b). При этом разность энергий связи доминирующей компоненты уровня $\mathrm{Sb} 4 d$ и компоненты с наименьшей энергией связи уровня $\mathrm{Ga} 3 d$ на сульфидированной поверхности после отжига при $360^{\circ} \mathrm{C}$ составляет $\sim 12.8$ эВ, т. е. данная компонента может содержать вклад связей $\mathrm{Ga}-\mathrm{Sb}$ в формирующихся кластерах $\mathrm{GaSb}$. При этом нельзя исключать, что и другие компоненты разложения спектра уровня $\mathrm{Ga} 3 d$ будут содержать вклад от кластеров $\mathrm{GaSb}$, поскольку эти кластеры не являются монокристаллическими и, следовательно, разность энергий связи объемных компонент $\mathrm{Sb}-\mathrm{Ga}(4 d)$ и $\mathrm{Ga}-\mathrm{Sb}(3 d)$ не обязательно должна быть $\sim 13.0$ эВ [20,21].

\section{4. Обсуждение результатов}

На основании полученных в ходе измерений спектров фотоэмиссии результатов были проанализированы особенности процесса сульфидной пассивации поверхности $\mathrm{GaSb}(100)$ в водном и спиртовом растворах сульфида аммония. Главной особенностью сульфидной пассивации поверхности $\mathrm{GaSb}(100)$ в исследуемых растворах является формирование неоднородного по химическому составу защитного слоя толщиной несколько десятков нанометров (рис. 5).

В процессе пассивации на поверхности полупроводника параллельно имеют место несколько различных 

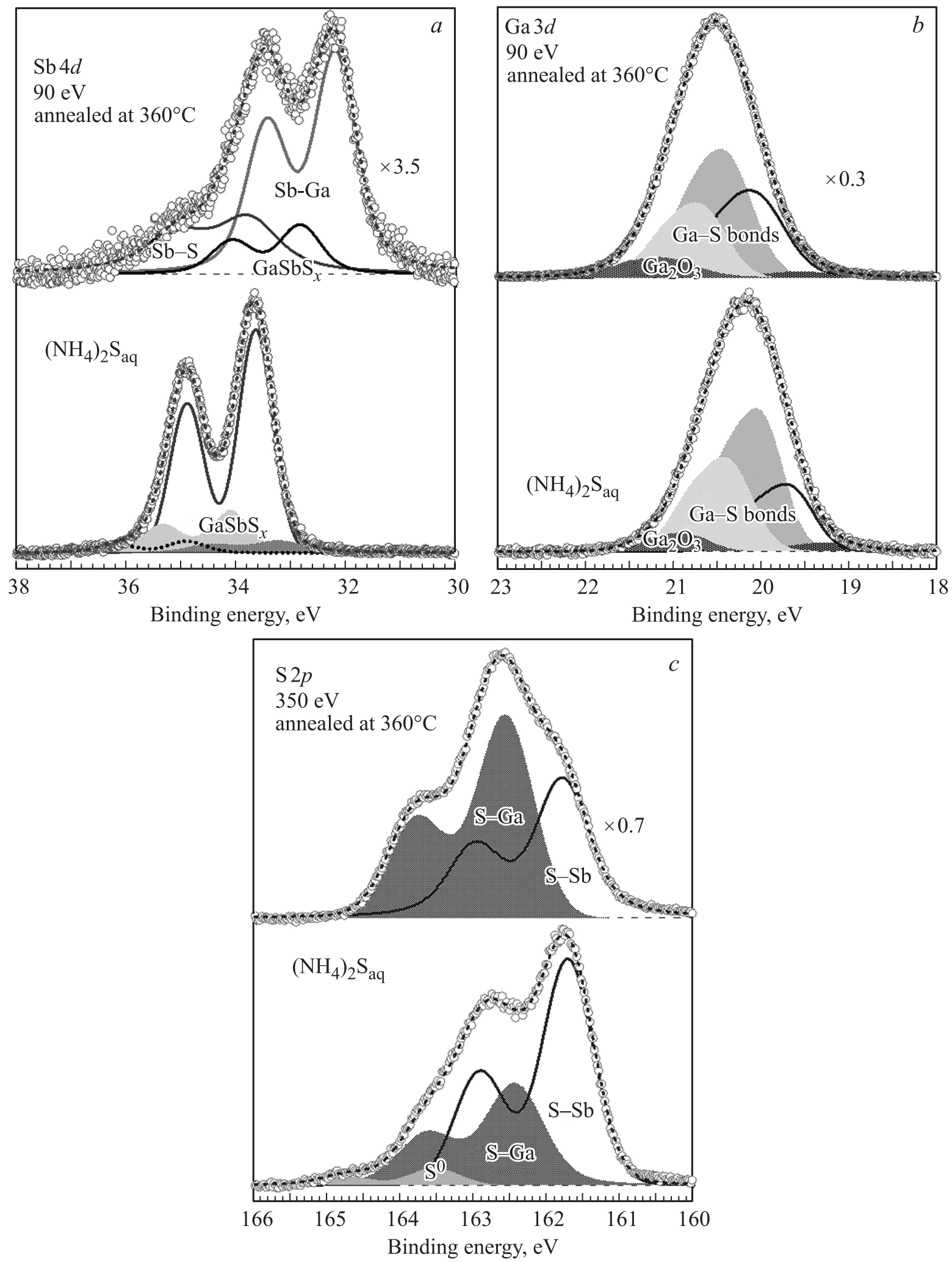

Рис. 7. Разложение спектров остовных уровней $\mathrm{Sb} 4 d(a)$ и $\mathrm{Ga} 3 d(b)$, измеренных при энергии возбуждения 90 эВ, а также спектров $\mathrm{S} 2 p(c)$, измеренных при энергии возбуждения 350 эВ на обработанной водным раствором сульфида аммония поверхности $\mathrm{GaSb}(100)$ и на этой же поверхности, подвергнутой отжигу в сверхвысоком вакууме при $360^{\circ} \mathrm{C}$. 
химических процессов. Как в водном, так и в спиртовом растворах протекает обменная реакция сульфидирования природного оксидного слоя, приводящая к образованию сульфидов сурьмы и галлия, регистрируемых методом РФЭС (рис. 3, 4).

Кроме того, в водном растворе постоянно происходит взаимодействие антимонида галлия с молекулами растворителя (воды):

$$
\begin{gathered}
2 \mathrm{GaSb}+5 \mathrm{H}_{2} \mathrm{O}=\mathrm{Ga}(\mathrm{OH})_{3}+\mathrm{HSbO}_{2}+3 \mathrm{H}_{2}, \\
2 \mathrm{GaSb}+7 \mathrm{H}_{2} \mathrm{O}=\mathrm{Ga}_{2} \mathrm{O}_{3}+2 \mathrm{HSbO}_{2}+6 \mathrm{H}_{2} .
\end{gathered}
$$

При измеренных значениях $\mathrm{pH}$ водных растворов $(\mathrm{pH} \approx 8-10)$ метасурьмяная кислота $\mathrm{HSbO}_{2}$ хорошо растворяется в воде и соответственно сурьма переходит в раствор. В результате соотношение $\mathrm{Ga} / \mathrm{Sb}$ уменьшается, что подтверждается данными РФЭС. Однако оксид галлия $\mathrm{Ga}_{2} \mathrm{O}_{3}$ не растворяется в воде и остается на поверхности, что подтверждается спектрами РФЭС (рис. 3,b), в которых регистрируется наличие связей $\mathrm{Ga}-\mathrm{O}$ при всех энергиях возбуждения, т.е. по всей толщине пассивирующего слоя. Эти реакции маловероятны в спиртовом растворе сульфида аммония при данных условиях из-за более сложного механизма взаимодействия между солью (сульфидом аммония) и растворителем (изопропиловым спиртом). Поэтому в спиртовом растворе сурьма в раствор не переходит, а оксид галлия не образуется, что подтверждается данными РФЭС (рис. 4,b). Следует отметить, что окисление поверхностных атомов полупроводника наблюдалось и при сульфидировании водным раствором сульфида аммония поверхности $\mathrm{InSb}(100)$ [25].

Таким образом, пассивация поверхности $\mathrm{GaSb}(100)$ в спиртовом растворе сульфида аммония приводит к практически полному удалению окисного слоя и формированию слоя, состоящего из сульфидов сурьмы и галлия. Слой, сформированный в водном растворе, имеет более сложный химический состав и включает в себя не только сульфиды галлия и сурьмы, но и соединения галлия с кислородом (оксиды и гидроксиды).

Раствор сульфида аммония является довольно сильным окислителем [26]. Поэтому в нем возможна реакция окисления $\mathrm{Sb}^{3+}$ в $\mathrm{Sb}^{5+}$, приводящая к образованию соединений не только 3-, но и 5-валентной сурьмы. Образовавшиеся сульфиды сурьмы (особенно 5-валентной) частично взаимодействуют с полисульфидами $\mathrm{S}_{n}^{2-}$, присутствующими в исходном водном растворе в результате гидролиза сульфида аммония [27]:

$$
\begin{aligned}
& \mathrm{Sb}_{2} \mathrm{~S}_{5}+3 \mathrm{~S}_{2}^{-}=2 \mathrm{SbS}_{4}^{3-}+3 \mathrm{~S} \\
& \mathrm{Sb}_{2} \mathrm{~S}_{3}+3 \mathrm{~S}_{2}^{-}=2 \mathrm{SbS}_{3}^{3-}+3 \mathrm{~S}
\end{aligned}
$$

В результате на поверхности полупроводника формируется слой элементной серы (рис. 7,c). Кроме того, образовавшиеся в результате реакций (3), (4) тиоантимонит-ионы $\left(\mathrm{SbS}_{3}^{3-}\right)$ и тиоантимонат-ионы
$\left(\mathrm{SbS}_{4}^{3-}\right)$ вступают в химическое взаимодействие с ионами галлия, образуя малорастворимые тиосоли (например, $\mathrm{GaSbS}_{3}, \mathrm{GaSbS}_{4}$ ), наличие которых подтверждается результатами РФЭС (рис. 7,a).

\section{5. Заключение}

Методом фотоэмиссионной спектроскопии при возбуждении синхротронным излучением исследован механизм процесса сульфидной пассивации поверхности $\mathrm{GaSb}(100)$ в водном и спиртовом растворах сульфида аммония $\left(\mathrm{NH}_{4}\right)_{2} \mathrm{~S}$, а также влияние природы растворителя на химический состав пассивирующего слоя, образующегося на поверхности полупроводника.

Обработка поверхности $\mathrm{GaSb}(100)$ водным или спиртовым раствором сульфида аммония приводит к формированию толстого (несколько десятков нанометров) покрытия, представляющего собой смесь различных бинарных и тройных сульфидов галлия и сурьмы.

В покрытии на поверхности $\mathrm{GaSb}(100)$, обработанной водным раствором сульфида аммония, обнаружено небольшое количество кислорода, связанного с атомами галлия, в то время как покрытие, сформированное после обработки в спиртовом растворе, не содержит кислорода.

Установлено, что соотношение атомных концентраций $\mathrm{Ga} / \mathrm{Sb}$ в сульфидном покрытии, сформированном при обработке раствором сульфида аммония в изопропиловом спирте, было стехиометричным, а в покрытии, сформированном в водном растворе сульфида аммония, концентрация галлия в $\sim 2$ раза превышала концентрацию сурьмы. Приповерхностный слой сульфидного покрытия (верхние 2-3 монослоя) в обоих случаях обогащен сурьмой. Отжиг сульфидного покрытия при $360^{\circ} \mathrm{C}$ приводит к удалению этой избыточной сурьмы и изменению приповерхностного изгиба зон диэлектрического сульфидного покрытия.

Измерения методом сканирующей электронной микроскопии выполнялись с использованием оборудования федерального ЦКП „Материаловедение и диагностика в передовых технологиях“ (ФТИ им. А.Ф. Иоффе, СанктПетербург).

\section{Список литературы}

[1] P.S. Dutta, H.L. Bhat, V. Kumar. J. Appl. Phys., 81, 5821 (1997).

[2] B.M. Nguyen, D. Hoffman, Y. Wei, P.Y. Delaunay, A. Hood, M. Razeghi. Appl. Phys. Lett., 90, 231108 (2007).

[3] A.W. Dey, B.M. Borg, B. Ganjipour, M. Ek, K.A. Dick, E. Lind, C. Thelander, L.-E. Wernersson. IEEE Electron Dev. Lett., 34, 211 (2013).

[4] Y. Mizokawa, O. Komoda, S. Miyase. Thin Sol. Films, 156, 127 (1988).

[5] P.S. Dutta, K.S.R. Koteswara Rao, H.L. Bhat, V. Kumar. J. Appl. Phys., 77, 4825 (1995). 
[6] A.Y. Polyakov, A.G. Milnes, X.L. Li, A.A. Balmashnov, N.B. Smirnov. Solid-State Electron., 38, 1743 (1995).

[7] J. Diaz-Reyes, E. Corona-Organiche, J.L. Herrera-Perez, J.G. Mendoza-Alvarez. Mod. Phys. Lett. B, 15, 804 (2001).

[8] M. Perotin, P. Coudray, L. Gouskov, H. Luquet, C. Llinares, J.J. Bonnet, L. Soonckindt, B. Lambert. J. Electron. Mater., 23, 7 (1994).

[9] Z.Y. Liu, T.F. Kuech, D.A. Saulys. Appl. Phys. Lett., 83, 2587 (2003).

[10] J.A. Robinson, S.E. Mahoney. J. Appl. Phys., 96, 2684 (2004).

[11] E.V. Kunitsyna, T.V. L'vova, M.S. Dunaevskii, Ya.V. Terent'ev, A.N. Semenov, V.A. Solov'ev, B.Ya. Meltser, S.V. Ivanov, Yu.P. Yakovlev. Appl. Surf. Sci., 256, 5644 (2010).

[12] D.M. Murare, N. Eassa, J.H. Neethling, R. Betz, E. Coetsee, H.C. Swart, J.R. Botha, A. Venter. Appl. Surf. Sci., 258, 6753 (2012).

[13] B. Wang, Z. Wei, M. Li, G. Liu, Y. Zou, G. Xing, T.T. Tan, S. Li, X. Chu, F. Fang, X. Fang, J. Li, X. Wang, X. Ma. Chem. Phys. Lett., 556, 182 (2013).

[14] M.V. Lebedev, E.V. Kunitsyna, W. Calvet, T. Mayer, W. Jaegermann. J. Phys. Chem. C, 117, 15996 (2013).

[15] D. Tao, Y. Cheng, J. Liu, J. Su, T. Liu, F. Yang, F. Wang, K. Cao, Z. Dong, Y. Zhao. Mater. Sci. Semicond. Proc., 40, 685 (2015).

[16] В.Н. Бессолов, М.В. Лебедев. ФТП, 32, 1281 (1998).

[17] T. Mayer, M. Lebedev, R. Hunger, W. Jaegermann. Appl. Surf. Sci., 252, 31 (2005).

[18] S. Tanuma, C.J. Powell, D.R. Penn. Surf. Interface Anal., 17, 927 (1991).

[19] J.J. Yeah, I. Lindau. At. Data Nucl. Data Tables, 32, 1 (1985).

[20] G.E. Franklin, D.H. Rich, A. Samsavar, E.S. Hirschorn, F.M. Leibsle, T. Miller, T.-C. Chiang. Phys. Rev. B, 41, 12619 (1990).

[21] M.T. Sieger, T. Miller, T.-C. Chiang. Phys. Rev. B, 52, 8256 (1995).

[22] D.A. Shirley. Phys. Rev. B 5, 4709 (1972).

[23] M.V. Lebedev, M. Shimomura, Y. Fukuda. Surf. Interface Anal., 42, 791 (2010).

[24] F.M. Túnez, J. Andrade-Gamboa, J.A. González, M.R. Esquivel. Mater. Lett., 79, 202 (2012).

[25] T.V. Lvova, A.L. Shakhmin, I.V. Sedova, M.V. Lebedev. Appl. Surf. Sci., 311, 300 (2014).

[26] Справочник химика, под ред. Б.П. Никольского, изд. 2-е (М.-Л., Химия, 1966).

[27] Ю.В. Карякин, И.И. Ангелов. Чистые химические вещества, изд. 4-е (М., Химия, 1974).

Редактор Л.В. Шаронова

\section{Effect of the sulfide ammonium solvent on surface passivation of $\mathrm{GaSb}(\mathbf{1 0 0})$}

\author{
M.V. Lebedev, T.V. Lvova, S.I. Pavlov, I.V. Sedova \\ loffe Institute, \\ 194021 St. Petersburg, Russia
}

Abstract $X$-ray photoemission spectroscopy and scanning electron microscopy are used to study the effect of solvent on the chemical composition of the passivating layer formed at the $\mathrm{GaSb}(100)$ surface. Treatment of the $\mathrm{GaSb}(100)$ surface with ammonium sulfide solutions causes formation of thick (a few tens of nanometers) coverage consisting of a mixture of different binary and ternary gallium and antimony sulfides. Annealing of the sulfide layer at $360^{\circ} \mathrm{C}$ in ultra-high vacuum results in partial desorption of the antimony from the surface, decomposition of ternary sulfides to binary constituents, and in the change in the surface band bending of this sulfide layer. 